\title{
Actitudes sociales y creencias populares sobre las amas de cría, reflejadas en el romancero tradicional: La nodriza del infante
}

\author{
CHARO MORENO \\ Fundación Ramón Menéndez Pidal
}

El análisis del romancero permite extraer conclusiones sobre la ideología de la comunidad en la que se transmite oralmente de generación en generación. Al tratarse de unos textos "abiertos" a transformaciones que permiten su adaptación a la realidad socio-cultural de aquellos que los escuchan, memorizan, interpretan y transmiten, deben tenerse en cuenta en su estudio algunas particularidades que diferencian a la literatura oral de otros géneros literarios.

Como texto abierto, no puede establecerse una versión única, sino que cada una de las variantes procedentes de la tradición oral a las que podamos acceder deben ser tenidas en cuenta como "textos" válidos, independientemente de sus cualidades poéticas, su fragmentarismo o sus variantes divergentes con el resto de la tradición ${ }^{1}$.

Al abordar el estudio de la balada La nodriza del infante editamos todas las versiones que pudimos recoger hasta la fecha, en un número de ciento setenta, en su mayoría inéditas ${ }^{2}$. Estas versiones corresponden a las cinco ramas de la tradición en las que ha sido documentada: en lengua francesa - tanto en Francia como Suiza y Canadá-, en occitano

1 Para la noción de apertura, ver los trabajos de Diego CATALÁn recogidos ahora en el volumen Arte poética del romancero oral. Parte 1, Los textos abiertos de creación colectiva (Madrid: Siglo XXI, 1997), y los estudios anteriores: "Análisis electrónico del mecanismo reproductivo de un sistema abierto: el modelo Romancero", Revista de la Universidad Complutense, 25 (1976), pp. 55-77; "Los modos de producción y "reproducción" del texto literario y la noción de apertura", Homenaje a Julio Caro Baroja (Madrid: Centro de investigaciones sociológicas, 1978), pp. 245-270; "Estudio de los modelos literarios abiertos", Ethnica (1982), pp. 53-66; "La conflictiva descodificación de las fábulas romancísticas", Culturas populares (Madrid: Universidad ComplutenseCasa de Velázquez, 1986), pp. 93-113.

2 Este artículo es una reelaboración del capítulo correspondiente de nuestra memoria de licenciatura que, con el título Análisis semiótico de estructuras narrativas abiertas: edición y estudio del romance "La nodriza del infante" (en adelante Análisis), fue leída en la Universidad Complutense de Madrid en 1995. 
y provenzal, en catalán - península y Baleares-, entre la comunidad sefardí de Tetuán y en castellano. La variedad geográfico-lingüística es otra de las características del romancero. Lógicamente cada comunidad lo adapta a la realidad en la que vive, en un constante proceso de actualización de sus contenidos, modificando los desenlaces, introduciendo nuevos elementos, e incluso transformando en última instancia el contenido ideológico ${ }^{3}$. Analizar la balada de La nodriza del infante, La nourrice du roi o La dida como se conoce en otras zonas lingüísticas, en cada una de las versiones de todas las áreas de la tradición, nos permitió estudiar la importancia que la figura del ama de cría tenía en el romancero. Esta balada la convierte en protagonista, pero su presencia en otros temas romancísticos es muy frecuente, como tendremos ocasión de comprobar.

La historia que narra La nodriza del infante tiene trazos trágicos: El ama se queda sola encargada de cuidar al infante, pero enciende un fuego, se duerme y el niño muere quemado. Cada una de las áreas de la tradición ofrece una solución distinta a la tragedia: En las versiones francesas y catalanas la intercesión de San Nicolás y de la Virgen, respectivamente, permiten que el niño vuelva a la vida, en el área sefardí el ama se suicida, mientras que en la castellana la joven muere por intervención divina, que la libra así del castigo ordenado por el rey. En otras ocasiones es condenada a la muerte social que significa el destierro.

Dado que el romance no figura en ninguna de las antologías de fácil acceso para el lector, transcribimos aquí dos versiones completas, una del área catalana y otra de la castellana:

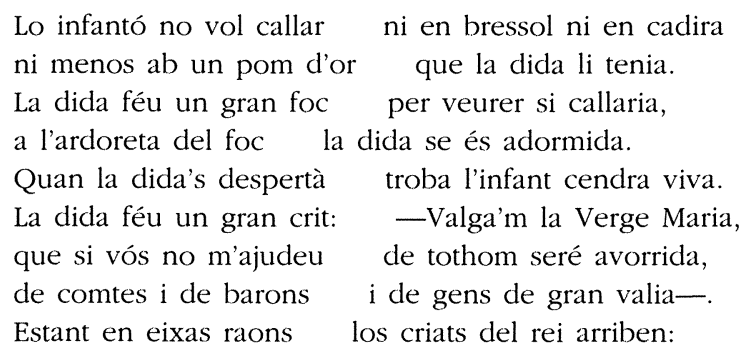

3 Ver nuestra memoria de licenciatura, pp. 9-21 y los trabajos de Jesús Antonio CID, "De La nourrice du roi a La nodriza del infante: Apertura de significados en la balada europea", Le Romancero ibérique: Genèse, architecture et fontions (Madrid: Casa de Velázquez, 1995), pp. 103-127, "El romancero oral hispánco: una poética de la variación oral", Culturas de la Edad de Oro, ed. J. M. Díez Borque (Madrid: Editorial Complutense, 1995), pp. 45-81 y "Von "La nourrice du roi" zu "La nodriza del infante": Bedeutungserweiterung in der europäischen Ballade", Jabrbuch für Volksliedforschung, 40 (1995), pp. 28-48. 
-Què teniu vós, la dideta, que n'esteu tan afligida?

-Só perdut un diamant lo millor que'l rei tenia.

—Dida, veus aquí diners aneu a la argenteria,

i compreu-me un diamant com aquell que'l rei tenia.

-Ne l's argenters no ne hi ha, tampoc en l'argenteria-.

També en aquest mateix punt lo rei i la reina arriben.

-Dida, a on teniu l'infant? ganes de veure'l tindria-

La dida se'en va al bressol troba l'infant que dormia ${ }^{4}$.

Un día por la mañana

¿Que viva el amor!

Teresina madrugaba

iQue viva la gala!

a empañar hijos del rey a la sombra de una retama.

Con el calor de la lumbre el sueño le atormentara.

Cuando despertó Teresina, cuando despertó la cuitada,

hallara el niño en carbón los pañales en cernada.

Voces daba Teresina, voces daba la cuitada.

Bien la oyera el rey su padre en altas torres en que estaba.

- ¿Tú qué tienes, Teresina, tú qué tienes, hija del alma?

-Tengo que se me quemó la mi mantilla de holanda.

- Si se quemó la de holanda te la compraré de grana encarnada.

Dame el niño, Teresina, que le quiero ver la cara.

-El niño estaba durmiendo es lástima que despertara.

-Dame el niño, Teresina, que le quiero ver la cara-.

Estando en estas palabras nel suelo cae desmayada.

Al otro día de mañana, Teresina ya finada;

dejó en su mano derecha una carta muy cerrada:

"Que den el cuerpo a la tierra que mi alma bien estaba" 5 .

Paralelo al interés que la figura de la nodriza ha despertado en el romancero, moralistas, teólogos y médicos han ofrecido sus comentarios, consejos y advertencias desde la antigüedad. La burguesía de los siglos XVI y XVII adopta la costumbres de la nobleza para sus niños, y tener un

4 Versión recogida por Marià Aguiló en el siglo XIX. Manuscrito conservado en la Abadía de Montserrat, Obra del Cançoner Popular Català, carpeta A-23, canción I.2, n. ${ }^{\circ}$ 7. Hemos consultado el microfilm de la Biblioteca de Catalunya y publicábamos esta versión, hasta entonces inédita en nuestro Análisis, n. ${ }^{\circ}$ II.7. Agradecemos tanto a la Abadía como a la Biblioteca de Catalunya permitirnos acceder a los fondos y editarlos.

5 Versión de Palacios del Sil (León), recitada por Eva González Fernández, y recogida por Pere Ferré, Amelia García Valdecasas, Fernando Gomarín y Madeline Sutherland, el 30 de junio de 1980. Se conserva en el Archivo Menéndez Pidal, ASORNorte, y permanecía también inédita hasta su edición en nuestro Análisis, IV.13. Agradecemos a la Fundación Menéndez Pidal su gentileza al permitirnos acceder y editar los documentos inéditos de su fondo. 
ama de cría es considerado un indicador de poder económico ${ }^{6}$ más que una necesidad, salvo en aquellos casos en los que la madre no pudiera alimentar a su hijo. Comienza entonces el discurso médico y social que considera que la mejor alimentación es la proporcionada por la propia madre $^{7}$, paralelo a la extensión de los consejos y normas sobre la elec-

6 Ver M." Carmen SimÓN PALMER, "La higiene y la medicina de la mujer española a través de los siglos XVI-XIX", Actas de las II jornadas de investigación interdisciplinar (Madrid: Universidad Autónoma, 1984), pp. 71-109. Ver también Juan GuTIÉRREZ DE GODOY, Tres discursos para provar que están obligadas a criar a sus bijos [sicl a sus pechos todas las madres, quando tienen buena salud (Jaén, 1629). Opinaba el Dr. Bonells, médico de los Duques de Alba: «El mal exemplo de las mugeres nobles arrastra las de estado medio, que ambiciosas de parecerseles buscan mil pretextos para no criar, y fingen mil males en caso de hallar resistencia de parte de los maridos. Con esto el abuso se ha calificado de prerrogativa de gente de forma, ¿y quál es la muger, que no aspire a parecerlo?", Jaime Bonells, Prejuicios que acarrean al género humano $y$ al Estado las madres que rehúsan criar a sus bijos y medios para contener el abuso de ponerlos en Ama (Madrid: Miguel Escribano, 1786), p. 31, punto 16.

7 Muchos son los autores que defienden la lactancia materna, entre otros: Damián CARBÓN, Libro del arte de las comadres o nodrizas y del regimiento de las preñadas y paridas $y$ de los niños (Palma de Mallorca, 1541) (BNM R/1322), f. ${ }^{\circ} 54 \mathrm{r}$; Juan DE LA CERDA, Vida privada de todos los estados de mujeres (Alcalá de Henares: Iván Gracián, 1594) (BNM R/4067), fs. 1r-7r, quien considera incluso que el dar el niño a una nodriza para criarlo es como si el niño fuera bastardo, ya que, como se creía que la leche era producto de la sangre, el niño alimentado por una nodriza lleva sangre que no es de su padre, para lo cual cita a Plutarco, y además el niño está en la madre nueve meses, pero con el ama veinticuatro: "la madre influye en el cuerpo, el ama en el cuerpo y en el alman; Juan ALONSO DE LOS RUICES FONTECHA, Diez privilegios para las mugeres preñadas (Alcalá de Henares: L. Martínez Grande, 1606) (BNM R/ 10681), f. ${ }^{\circ}$ 170r; Bernardo GORDONIO, Tratado de los niños y regimiento del ama, en Obras (Madrid: Antonio Gonçalez de Reyes, 1697), p. 307; Josepha AMAR y BORBÓN, Discurso sobre la educación física y moral de las mujeres (Madrid: Impr. Benito Cano, 1790), pp. 23-31; José Jorge DE LA PENAA, Ensayos sobre la perfección del hombre en la extensión de su ser (Madrid: Imprenta del colegio nacional de sordo-mudos, 1842), p. 187. Ver también el trabajo de Rosa BaLlester, "Factores biológicos y actitudes vigentes frente a la infancia en la sociedad española del antiguo régimen", Asclepio XXXV (1983), pp. 343-357. El estudio de las opiniones que sobre el tema de la lactancia materna tenían los médicos medievales castellanos puede leerse en Andrea María BAU, "Los cuidados del recién nacido en España a través de la teoría médica (siglos XIII a XVI)", Medicina y sociedad: curar y sanar en la España de los siglos XIII al XVI, María Estela González de Fauve (coord.) (Buenos Aires: Instituto de Historia de España 'Claudio Sánchez Albornoz', Facultad de Filosofía y Letras, Universidad de Buenos Aires, 1996), pp. 167-194; sobre la lactancia materna y de amas de cría de siglos posteriores ver Joan SHERwOOD, "The Ideology of Breast-feeding: Deconstructing Spanish Medical Texts Concerning Nursing Women at the End of the Eighteenth Centuryn, Alain Saint-Saëns (ed.), Religion, Body and Gender in Early Modern Spain (San Fran- 
ción de una buena nodriza. En este período, además, se transforma la visión del niño, que de ser continuador del linaje pasa a formar parte plena de la vida familiar, al igual que la familia se convierte en una cuestión más de pareja que de clan ${ }^{8}$.

En este artículo analizaremos la relación entre las ideas generalizadas sobre las amas y la presencia del personaje en el romancero, las discrepancias y las coincidencias ideológicas.

Si la nodriza de nuestro romance es acusada de haber sido negligente con el niño que muere quemado por su causa, la misma denuncia recaía sobre otras amas de cría. En efecto, eran muy elevadas las muertes de los pequeños confiados a sus cuidados. A ojos de la sociedad, el ama era culpable del fallecimiento del niño, independientemente de que su implicación en la muerte fuera directa o si el niño moría por accidente o causas naturales. El índice de mortalidad aumentaba considerablemente si el niño vivía en la casa de la nodriza ${ }^{9}$, del orden de más de un tercio so-

cisco: Mellen Research U.P., 1991), pp. 94-107. Para los autores clásicos, ver Javier HoYo CALlEJA, "La primera alimentación del hombre", Gerión, anejos 3 (1991), pp. 195204. Las opiniones de los juristas han sido recogidas por León Carlos Álvarez SANTALO, "Anormalidad y códigos de conducta de la familia en el Antiguo Régimen: la doctrina religiosa sobre el abandono de niños", F. CHACón (ed.), Familia y sociedad en el Mediterráneo Occidental. Siglos XV-XIX (Murcia: Universidad, 1987), pp. 43-68. Sobre la opinión de autores franceses medievales, ver Danièle ALEXANDRE-BIDON y Didier LETT, Les enfants au Moyen Age, $V^{e}-X v^{e}$ siècles (Paris: Hachette, 1997), pp. 123-4 y Danièle ALEXANDRE-Bidon y Monique Closson, L'enfant à l'ombre des cathédrales (Lyon: Presses Universitaires de Lyon, CNRS, 1985), pp. 112-3. Es interesante este estudio al ofrecer con detalle el mundo iconográfico que plasma la lactancia durante la Edad Media. La obra de tratadistas franceses posteriores se analiza por Yvonne KNIBIEHLER y Catherine FouQueT, L'histoire des mères du Moyen Age à nos jours (Paris, 1980), p. 86. También en el refranero encontramos ejemplos de la preferencia por la lactancia materna: "Más vale sudor de madre que leche de aman, en Antonio CASTILLO DE LuCAS, Refranero médico (Madrid: CSIC, 1944), p. 170.

8 Remitimos al imprescindible trabajo de Philippe ARIÈs, L'enfant et la vie familiale sous l'ancien régime (Paris: Plon, 1960), y al más reciente y conciso estudio de Jacques GÉLIS, "The Evolution of the Status of the Child in Western Europe: From the Collective Body to the Private Body", Social Research, 53 (1986) 4, pp. 689-704, en especial p. 690.

9 "La doute n'existe plus, c'est à l'industrie nourricière qui'il faut attribuer ces morts si nombreuses que l'on ne constate guère que là où elle s'exerce". León LE FORT, "La mortalité des noveau-nés et l'industrie des nourrices en France", Revue des deux mondes (15 marzo 1870), pp. 363-391: 372. El riesgo es menor si el niño vive con la nodriza en casa de sus padres. Considera Le Fort que las causas de mortalidad son "la faiblesse native, le défaut de soins, insuffisance ou la mauvaise qualité de la nourriture", p. 367. Ver Marie-France MoRel, "Théories et pratiques de l'allaitement en France au XVIII ${ }^{\mathrm{e}}$ sièclen, Annales de Demographie Historique (1976), pp. 393-427: 417. 
bre el total de niños entregados a sus cuidados ${ }^{10}$. Las difíciles condiciones de vida de la mujer y la atención que debía prestar tanto a otros miembros de su familia como a las labores agrícolas y domésticas condicionaban notablemente la atención y el cuidado dedicados al niño ${ }^{11}$.

La situación no era mucho mejor si el niño seguía viviendo en casa de sus progenitores. Desde la Edad Media se manifiesta el temor a que muriera ahogado al dormir en la misma cama que la nodriza, o que su madre. Además, estaba considerado un medio habitual de ocultar mediante un accidente el infanticidio ${ }^{12}$. En Castilla el temor se plasma en un poema jocoso de Fernández de Heredia:

$Y$ ha dado en tanto recelo mi gran locura de loco que lo que duermo es tan poco,

Bibliografía del siglo XIX sobre el tema, preparada por A. ARMENGAUD, Annales de Demographie Historique (1973), p. 349. Ver además los trabajos de Paul Galliano, "La mortalité infantile (indigénces et nourrissons dans la baulieue sud de Paris à a fin du XVIII ${ }^{\mathrm{e}}$ siècle (1774-1794), Annales de Demographie Historique (1966), pp. 139-177, especialmente pp. 156-177; Catherine ROLLET, "Allaitement, mise en nourrice et mortalité infantile en France a la fin du XIX ${ }^{\mathrm{e}}$ siècle", Populations, 33 (1978) n. ${ }^{\circ}$ 6, pp. 1189-1202.

10 Para Francia ver A. Chamoux, "Mise en nourrice et mortalité des enfants legitimes", Annales de Demographie Historique (1973), pp. 418-422. En Castilla las cifras son similares, Cfr. Claude LARQUIE, "La mise en nourrice des enfants madrilénes, XVII siècle", Revue d'bistoire moderne et contemporaine, 32 (1985), pp. 125-144: 137.

11 MOREL, p. 415. El romancero apenas documenta la elevada mortalidad infantil de los niños entregados al cuidado del ama. Tan sólo contamos con una referencia en el famoso romance titulado Querella de la duquesa de Guimarães, más conocido por su incipit: "Quexome de vos el rein: “[...] y en prisiones muy esquiuas / en que vos me haueys echado // con vna hija que tengo / que otro bien no me ha quedado // que tres hijos que tenia / haueys me los apartado // el vno es muerto en Castilla / el otro desheredado / el otro tiene su ama / no espero verlo criado // por el qual pueden dezir / innocente desdichadon. Citamos por la Silva de romances (Zaragoza, 1550-1551), ed. de Antonio Rodríguez-Moñino (Zaragoza: Ayuntamiento, 1970), Primera parte de la Silva (Zaragoza, 1550), pp. 173-4. El texto sin duda resulta ambiguo, y no podemos saber si la duquesa está segura de que ella morirá antes de que el niño nazca o si fallecerá éste en su infancia.

12 Ver J.-L. Flandrin, "L'attitude à l'egard du petit enfant et les conduites sexuelles dans la civilisation occidental", Annales de Demographie Historique (1973), pp. 143-210: 166-167 y 175 para ejemplos de teólogos franceses del siglo XVII; Pierre Gurral et Guy THULliter, La vie quotidienne des domestiques en France au XIX siècle (Paris: Hachette, 1978), p. 158. Ver además P. RichÉ, "L'enfance dans le haut Moyen Age", Annales de Demographie Historique (1973), pp. 95-98: 96. No sólo podía morir el niño por ahogamiento al dormir en la cama, sino por la presión contra el pecho de su propia nodriza, dormida al alimentarle, $c f r$. Ambroise Paré, en KNibieHler y Fouquet, p. 91. 
que más duermo cuando velo.

Ya que duermo estoy temiendo de esta gran voluntad mía,

que es un ama que me cría, que me ha de ahogar durmiendo ${ }^{13}$.

Y debía de ser muy frecuente el caso de ahogamiento del niño, tal como se indica en otro texto del siglo xviI, del doctor Christobal Pérez de Herrera:

[...] las calenturas, pues con ellas y el grande abrigo, assi de ropa, como del ayre que con braseros y sahumerios alteran y calientan, sin darles gota de agua que les humedezca, aliuie y refresque, contrariandose a las calidadess calientes y secas de las causas referidas, es muy cierto el ahogarse, faltando la respiracion del ayre fresco que les da vida, como a todos los animales haze ${ }^{14}$.

La necesidad de aclarar las verdaderas causas de la muerte se pone de manifiesto en estos comentarios forenses del siglo XVII:

Para conocer de qué murió algún niño que hallaron muerto a deshoras junto a su ama: Ya se han visto las señales de las heridas en cada miembro, resta proponer otras de ciertos géneros de muerte extraordinarias. Acerca de las quales suele auer muchas barajas y pleitos, haziendo juezes dellos a los Medicos y Cirujanos. Acontece pues que el ama con poco miramiento, y desvergüença, o por estar tomada del vino, se eche sobre su criatura, de manera que la halla $n$ ahogada. Preguntase en tal caso, si por culpa del ama, o por alguna enfermedad encubierta del niño, o de la niña sucedió la muerte? La qual questión en juizio, o fuera dél satisfaremos, dizie $n$ do, que si el niño estaua muy bueno poco antes, si no andaua con achaques y quexas, si tiene la boca y narizes hinchadas, y llenas de espumajos, si tiene la cara amoretada, con $n$ un color como de violetas, y si abrie $n$ dose luego esta $n$ los pulmones hinchados, y bahea $n$ do con espumas, y sanos los otros miembros, todo esto es argumento de averse ahogado la criatura con alguna fuerça exterior ${ }^{15}$.

Algunos médicos franceses del siglo XVII consideran que el dormir con el niño supone un peligro para éste, no sólo por el riesgo de ahogamiento,

13 Del poema "Un sueño con cierto misterio", recogido en Obras (Madrid: EspasaCalpe, 1975), 2. ${ }^{a}$ ed., p. 20, vv. 500-507. Se encuentra con ligeras variaciones gráficas en el ms. 2621 de la Biblioteca Nacional de Madrid, en letra del siglo xvi, con título del poema: Un sueño en manera de chiste, f. ${ }^{\circ} 80 \mathrm{r}-84 \mathrm{r}$, estrofa 3, y fue incluido en Las obras de Ioan Fernández de Heredia, assí temporales como espirituales... (Valencia: Juan de Rey, 1562), publicadas póstumamente por su hijo. Ver José Manuel Blecua, "Versos nuevos de Fernández de Heredia", Suma de estudios en bomenaje al ilustrísimo señor Doctor Ángel Canellas López (Zaragoza, 1969), pp. 125-147.

14 Dr. Christobal PÉREZ DE HERRERA, Defensa de las criaturas de tierna edad (Valladolid: Luis Sanabez, 1604) (BNM 2/51863), f. ${ }^{\circ} 43 \mathrm{v}$.

15 Juan Fragoso, Cirıgia Universal (Alcalá de Henares: J. Gracián, 1621), p. 546. 
sino porque aleurs forces vitales sont insensiblement absorbées par les personnes avec lesquelles ils couchent ${ }^{16}$.

La nodriza del infante ofrece versiones en las que el niño muere efectivamente ahogado, pero cuando están condenando a su nodriza el niño milagrosamente explica que no ha sido ella quien le ha matado, sino una simple flema:

Penchés pas ma nourriça qu'ou a pas meritat:
Acos era una fléuma que m'aviè estoufat! ${ }^{17}$

Sin embargo, como comentábamos, la muerte le viene al infante en la mayoría de las versiones del romance al quemarse con el fuego que su ama había encendido para que se calentara. En numerosos casos se justifica el sueño que se apodera de la nodriza por el propio calor, lo que supone en buena medida un intento de suavizar su culpabilidad ${ }^{18}$.

La opinión general, por el contrario, suele relacionar estos accidentes con el descuido de sus obligaciones por parte de la negligente nodriza:

Si vous laissez faire la nourrice, elle ne sortirait jamais Bébé pour le mener boire le soleil, respirer l'air de verdure des squares. Paris, au fond, l'excède: et elle préféreriat rester près du feu, sans lumière, l'enfant aux genoux, le nez dans les cendres comme à la campagne, dormant, des heures durant, de son lourd sommeil de paysanne ${ }^{19}$.

Con el fin de evitar la muerte de los niños puestos en manos de cualquier mujer que pudiera alimentarlos, surgen en Francia ordenanzas que establecen el procedimiento sobre la elección de las nodrizas y el control sobre su trabajo. La ley de 1 de junio de 1756 obligaba a las

16 MOREL, p. 416, la autora recoge opiniones médicas contrarias, defendiendo así la relación natural entre la madre, la nodriza y el niño (p. 416). Ver también los textos recogidos en el trabajo de François Loux y la propia Marie-France MoREL, "L'enfance et les savoirs sur le corps: Pratiques médicales et pratiques populaires dans la France traditionnelle", Ethnologie française, VI (1976), pp. 309-322.

17 Versión de Montpellier publicada por Charles BORDES, Onze chansons $d u$ Languedoc... (Paris: Editions de la "Schola", 1906), pp. 6-7. Cfr. Análisis, n. ${ }^{\circ}$ I.17.

18 "La dida féu un gran foc / per veurer si callaria, // a l'ardoreta del foc / la dida se és adormida", versión inédita recogida por Marià Aguiló en el siglo XIX, procedente de sus trabajos de campo conservados en la Abadía de Montserrat, Obra del cançoner popular català, carpeta A-23, ver Análisis, n. ${ }^{\circ}$ II.6.

19 Alphonse DAUDET, Souvenirs d'un homme de lettres. Notes sur Paris (1888), p. 430, citado por Guiral et Thuiluier, p. 159. En el ámbito castellano se recomendaba que la nodriza tenía que "ser veladora: no tenga fuerte sueño, facil para leuantarse para pacificar el niñon, y cita a Galeno como auctoritas, CARBó, f. ${ }^{\circ}$ LV-r. 
nodrizas a evitar el dormir con el niño en la misma cama ${ }^{20}$; la del 9 de agosto de 1828 exigía tener un certificado de "bonne vie et moeurs", medios económicos y encargarse de un sólo niño. A diferencia de la normativa, en el folklore en general encontramos el motivo de varios niños alimentados por una sola nodriza como elemento propicio para sellar unos vínculos igual de fuertes que los de sangre. En el romance catalán de $L a$ peregrina el hecho de que niño y niña tengan la misma "dida", la misma ama, supone una predisposición desde la cuna a sellar su amor:

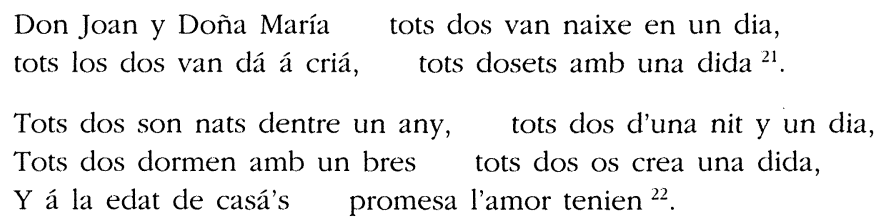

Los lazos entre los niños criados por la misma nodriza eran tan sólidos que supusieron la creación de disposiciones específicas en la Castilla medieval para evitar ulteriores problemas en los herederos al trono:

Et ssi ffuere ama que crie otro ffijo o ffija del rrey o de la rreyna mjentre quel diessen la leche, ffaze aleue; et deue morir por ello et perder las tres partes de lo que oujere ${ }^{23}$.

Volviendo a la normativa francesa, era necesario hacer constar si la nodriza tenía cuna, con el motivo de evitar que durmiera el niño con ella en su cama, y "garde-feu" para la chimenea, claro indicador del alto número de accidentes que sufrían los niños por el fuego ${ }^{24}$.

La ley Roussel, de 23 diciembre 1874, afecta sobre el papel a todos los niños menores de dos años a los que les atiende una nodriza. Introduce la legislación en favor del hijo de la nodriza, que debe tener un mínimo

20 Fanny FAY-SALLOIS, Les nourrices à Paris au XIX siècle (Paris: Payot, 1980), p. 26, la reglamentación pp. 25-33.

21 Cfr. Manuel Milà i Fontanals, Romancerillo Catalán (Barcelona: A. Verdaguer, 1882), n. ${ }^{\circ} 219$, pp. 181-185, en concreto p. 181. Téngase en cuenta también el motivo folklórico del nacimiento en un mismo día, indicativo del destino común de ambos personajes.

22 Ibid., p. 184.

23 Alfonso X, Espéculo, en Leyes de Alfonso X.1, Espéculo, ed. Gonzalo Martínez Díez y José Manuel Ruiz Asencio (colab.) (Ávila: Fundación Sánchez Albornoz, 1985), Ley VI, "Cómmo deuen sseer onrradas e guardadas las amas que crian los ffios del rrey e qué pena deue auer qui yoguiere con alguna dellas", p. 172.

24 LE FORT, p. 379. 
de siete meses para que la madre pueda ejercer como tal. Las condiciones óptimas de la nodriza para realizar su labor venían avaladas por el estado de salud de su propio hijo, en el caso de que éste viviera. Si la nodriza se trasladaba fuera de su casa para cuidar al niño, su hijo no podía quedar abandonado sino que debía ser confiado a su vez a otra nodriza y se verá sometido a inspecciones incluso en el caso de que esté bajo tutela de un familiar ${ }^{25}$. Además, en París y en las grandes ciudades en las que existía un Bureau des Nourrices, un médico examinaba a las candidatas y todos sus datos quedaban registrados, siguiéndose de cerca también el estado de su hijo ${ }^{26}$. Aún así el control sobre todos los casos no era completo, menos aún en aquellas poblaciones en las que no existía el Bureau.

El examen médico de la nodriza debía ser exhaustivo, pero en las recomendaciones de los doctores pervivían prejuicios sobre su físico, hasta el punto que llegaban a descartar a las nodrizas rubias por ser predispuestas a la tuberculosis o a las pelirrojas porque transpiraban demasiado $y$ el niño no querría comer ${ }^{27}$.

En esta ocasión las preferencias físicas expresadas en el romancero difieren del modelo de perfección francés ${ }^{28}$ :

-Quédate con Dios, el cuerpo, San Miguel te pese el alma,

el niño lo llevo yo, le tengo de buscar ama;

aunque sea morenita tenga la leche delgada (El bijo póstumo) ${ }^{29}$

25 Cfr. Anne MARTIN-FUgiER, "Le fin des nourrices", Le mouvement social (1978), n. ${ }^{\circ}$ 105, pp. 11-32: 30. Ver A. ARmENGaud, "L'attitude de la société à l'égard de l'enfant au XIX ${ }^{\mathrm{e}}$ siècle", Annales de Demographie Historique (1976), pp. 303-312.

26 MOReL, p. 412, y pp. 417-418.

27 Dr. Adolphe Olivier, Annales de la polyclinique de Paris (febrero 1892), cfr. Martin-Fugier, p. 16. Comenta la autora que en los casos en que el estado de salud del hijo de la nodriza no era el más conveniente para que aprobara el examen médico, se producía el esperable cambio de criatura, ver p. 19. Para fuentes medievales castellanas sobre la elección de la nodriza por sus características físicas, ver BAU, pp. 184-185.

28 Difieren notablemente, pues para el engañado marido de La aduiltera, ésta no debe seguir alimentando a sus propios hijos tras conocer su relación extramatrimonial. El apelativo que emplea para calificar negativamente el estado de su leche es significativo de los diferentes prejuicios que caracterizan a una comunidad: "Levantáte, perra, levanta, / levantate que no duermas, // da mamar esa criatura / d'ese leche tan franseza", en J. MARTínez Ruiz, "Poesía sefardí de carácter tradicional (Alcazarquivir)", Archivium, XIII (1963), pp. 79-214: 153, vv. 15-16.

29 Romancero General de León [en adelante $R G L$ ] (Madrid: Seminario Menéndez Pidal, 1991), t. I, n. ${ }^{\circ} 1$, p. 10. En el mismo romancero, p. 11, encontramos otra versión en la que se indica que la leche debe tener la misma cualidad: "que este niño que aquí llevo / yo le buscaré un ama, // que sea rosa del pecho / y de la leche livianan. 
Se produce una especialización geográfica, apreciándose las nodrizas procedentes de Cantabria en España y las de Normandía y Lorena en Francia ${ }^{30}$.

Además, se prefería que fueran mujeres no primerizas y, si estaban casadas, con sus maridos alejados de ellas, con el fin de evitar un nuevo embarazo que "estropeara" la leche ${ }^{31}$ :

-No lo des a mujer viuda, tampoco a recién casada, déselo a una tía suya, que la quiera como al alma, y cuando le dé la teta que le diga estas palabras:

30 En el siglo xIx las mujeres cántabras emigraban a Madrid en busca de su salario y el de toda su familia. Ser del Norte de la península suponía un aval sobre la calidad de la leche, de ahí que durante el reinado de Isabel II se realizara una labor de búsqueda por parte de los médicos de la Corte en Asturias, Santander y Burgos. Ver Luis CORTÉs ECHANOVE, Nacimiento y crianza de las personas reales en las cortes de España (Madrid: CSIC, 1958), pp. 311-313. La oferta sin embargo estaba en el centro de Madrid, con las nodrizas esperando en las calles. El retrato de la situación y la crítica a las madres que no querían criar a sus hijos puede leerse en "Las pasiegas", Teatro social del siglo XIX (Madrid: Tipograf. F. de P. Mellado, 1846), pp. 315-321. La parodia a la rústica nodriza alcanza tintes crueles en Galdós: "Era el ama rolliza y montaraz, grande y hombruna, de color atezado, ojos grandes y terroríficos, que miraban absortos a las personas como si nunca hubieran visto más que animales. Se asombraba de todo, se expresaba con un como ladrido entre vascuence y castellano que sólo mi cínife entendía, y si algo revelaba su ruda carátula era la astucia y la desconfianza del salvaje. Cuando, obediente a la consigna de doña Cándida, tomaba al chiquillo para alimentarle y se sacaba del pecho con dificultad un enorme zurrón negro, creía yo que aquello iba a sonar como las gaitas de mi país", en El amigo Manso, Benito PÉrez Galdós, Obras completas, t. IV (Madrid: Aguilar, 1954), pp. 1200-1201. En los mismos términos critica a las nodrizas francesas Alphonse Daudet: "La première tradition, chez les nourrices, comme chez les filibustiers allant au pillage, est d'arriver les mains vides, sans bagages encombrants; la seconde est de se procurer une grande malle, la malle a serrer la denraie. Car vous aurez beau la choyer et la soigner, cette sauvagesse ainsi introduite chez vous, et qui détonne d'abord si étrangement parmi les élégances d'un intérieur parisien avec sa voix rauque, son patois incompréhensible, sa forte odeur d'étable et d'herbe [...]", cfr. Guiral y Thulliers, p. 154.

31 Martin-Fugier, pp. 19-20; P. Bourdelais y J.-Y. Raulot, "Des risques de la petite enfance à la fin du XVIII" siècle", Annales de Demographie Historique (1976), pp. 305318: MOREL, pp. 410-411; Jean-Baptiste BÉCOEUR, Memoire sur la lait (manuscrito de 1771, Biblioteca Municipal de Metz), publicado por F. Y. LE MOIGNE en Annales de Demographie Historique (1976), pp. 391-393: 392. En el ámbito castellano, hace las mismas indicaciones Alonso DE LOS RUICES DE FONTECHA, f. ${ }^{\circ} 170 \mathrm{v}$. Por el mismo motivo se castiga en Las siete partidas a aquel que fuerce a las amas de palacio, "porque si tal cosa feciesen en quanto diese la leche al niño, podrie seer que vernie por ello a grant enfermedat o a muerte, título XIV, ley IV, citamos por la ed. de la Real Academia de la Historia (Madrid: Atlas, 1972), p. 130. 
"Mamá la teta, mi vida, mamá la teta, mi alma, que naciste por los montes pudiendo nacer en casa"

(El bijo póstumo) $)^{32}$

En los textos medievales castellanos queda constancia de la necesidad de que la nodriza del hijo del rey o del héroe sea de alto linaje ${ }^{33}$. La literatura tan sólo refleja lo que es un hecho en la realidad, ya que la mayoría de las nodrizas de la corte pertenecían a la nobleza, por ejemplo las de Alfonso III, Sancho II, don Denís, Alfonso X, Alfonso XI y Fernando IV ${ }^{34}$. Del mismo parecer es Don Juan Manuel:

Otrosí a sus fijos, segund el mío entendimiento, dévelo fazer en esta manera: bien en quanto fueren tan niños que non [saben] fablar nin andar, dévenles catar buenas amas, que sean de la mejor sangre et más alta et más linda que pudieren aver. Ca çierto es que del padre o de la madre en afuera, que non ay ninguna cosa de que los omnes tanto tomen, nin a qui tanto salgan nin a qui tanto semejen en sus voluntades et en sus obras, como a las amas cuya leche mamaran ${ }^{35}$.

Díaz de Games en El victorial refleja las mismas inquietudes en la búsqueda de un ama que "fuese buena, e de buen linaxe, e limpia, moça

$32 R G L$, t. I, n. ${ }^{\circ} 3$, p. 11. El nacimiento en el paisaje abrupto de la sierra o la montaña, tal como le sucede a Montesinos, a quien el lugar le da nombre, es un elemento folklórico común en numerosos romances, así como de los libros de caballerías y de la épica, llegando a las leyendas fundacionales como en el caso de Sancho Abarca. Ver Alberto Del Río Nogueras, "Leyendas épicas en el Aragón medieval: Sancho Abarca en los orígenes del reino", I Curso sobre lengua y literatura en Aragón (Edad Media) (Zaragoza: Institución Fernando el Católico, 1991), pp. 133-157, en concreto pp. 142-144.

33 Ver José Manuel CACHO BleCUA, "Nunca quiso mamar lech de mugier rafez (Notas sobre la lactancia. Del Libro de Alexandre a don Juan Manuel)", Vicente BELTRÁN (ed.), Actas del I Congreso de la Asociación Hispánica de Literatura Medieval. Santiago de Compostela, del 2 al 6 de Diciembre de 1985 (Barcelona: PPU, 1988), pp. 209-224, y BAU, p. 186.

34 Ver C. MiCHAËLIS, "Randglossen zum altportugiesischen Liederbuch. I. Der Ammenstreit", Zeitschrift für romanische Philologie, XX (1896), 145-218, trabajo recientemente revisado por Vicenç BeLtrán, "Tipos y temas trovadorescos, XV. Joan Soarez Coelho y el ama de don Denis", Bulletin of Hispanic Studies, LXXV (1998), pp. 13-43. cfr. p. 19.

35 Libro de los estados, ed. Ian R. Macpherson y Robert Brian Tate (Madrid: Castalia, 1991), pp. 196-7. Don Juan Manuel continúa exponiendo ejemplos a favor de a elección de la nodriza de alto linaje, tal como lo defendiera Alfonso X en Las Partidas, ver Beltrán, pp. 21-2, donde también se recoge la siguiente cita del Libro de Alexandre: "El infante Alexandre luego en su ninnez / enpeço a mostrar que serie de gran prez / nunca quiso mamar leche de muger rafez / si non fuesse de linage o de gran gentilez", ed. de F. Marcos Marín (Madrid: Alianza, 1984), estrofa 7. 
e apuestan ${ }^{36}$. De la misma opinión eran los tratadistas medievales franceses ${ }^{37}$.

En el romancero se prefiere por lo general que la mujer que ha de encargarse de los niños sea de origen noble, preferiblemente, como en el caso anterior, de la propia familia, tal como podemos comprobar en estas versiones del romance de La infanta seducida:

-Que me lleves este hijo
$\begin{aligned} & \text { No me lo lleves a aquella dama lo criara. } \\ & \text { llévaselo a mi madrastra de los siete criara, } \\ & \text { que es leche de soberana }{ }^{38} \text {. }\end{aligned}$
-Anda, vete, conde Florez, búscale una buena ama
que sea buena de leche y de sangre mejor rama ${ }^{39}$.

Las alteraciones en la leche de la nodriza eran una preocupación constante, y su estado de ánimo también podía afectar negativamente, por lo que se procura no contrariarlas:

36 Gutierre DíEz DE GAMEs: El victorial, ed. Alberto Miranda (Madrid: Cátedra, 1993), cap. XVIII, p. 256. Narra inmediatamente antes cómo es rechazada una nodriza que no cumple estas condiciones: "En besándole, diz que era ella dueña tan umana e de sotil sentido, que le olió que avía mamado leche agena, de otra muger. E non se queriendo confiar tanto en su sentido, hizo juramentar todas las dueñas e donzellas que a la sazón eran en la cámara donde su hijo estava, e dixéronle cómo una dueña le avía dado a mamar. Tomó entonces su hijo e hízolo meter en un manto e traerlo a una parte e a otra; e tanto lo fizo hasta que le hizo lançar la leche, de lo cual dizen que fue no tan sano de allí adelante, e que siempre ovo la color demudada por aquella razón, aunque era fuerte caballero". Un ejemplo similar se encuentra en La Gran Conquista de Ultramar, ed. de L. Cooper (Bogotá: Instituto Caro y Cuervo, 1979), t. I, p. 300.

37 Doris Desclais BerKVAm, Enfance et maternité dans la littérature française des XII et XIIT siècles (Paris: Honoré Champion, 1981), pp. 47-49.

38 Versión inédita recogida por Eduardo Martínez Torner, en Olga (Asturias) en 1916. Manejamos el original conservado en el Archivo Menéndez Pidal. Forma parte esta versión del corpus de nuestra tesis doctoral sobre el romance La infanta seduci$d a$, en la actualidad en preparación.

39) Versión también inédita conservada en el Archivo Menéndez Pidal, recogida en Luarca (Asturias) por Aurelio de Llano. Por otra parte, José Antonio Maravall en POder, bonor y élites en el siglo XVII (Madrid: Siglo XXI, 1979), p. 52, recoge esta expresión de Baños de Velasco, refiriéndose a Saavedra Fajardo: "Si se mirase con descuidos la nobleza, no es culpa de la sangre heredada, mas de viciosidad de la leche que la alimentón. Indica a continuación Maravall que también puede culparse a la nodriza no sólo por las cualidades transmitidas al niño, sino por otro delito, según comenta Salas Barbadillo en El caballero puntural (Madrid, 1614), f. ${ }^{\circ}$ 16: si no se comporta un hombre principal como debía por su estado ajuzgo que no es hijo de aquellos padres cuya hacienda y calidad heredó, sino que el ama hizo algún cambion. 
Hay niños que padecen cólicos violentos por haberse impacientado sus nodrizas antes de darles de mamar, y otros que han muerto con horribles convulsiones porque las nodrizas les dieron el pecho en el momento de hallarse coléricas ${ }^{40}$.

Estos trastornos anímicos podían estropear la leche de la nodriza, como le sucede a la protagonista de las versiones sefardíes de nuestro romance:

no déis al prinze esa leche desmaída.

O bien:

no le des al niño esa leche consumida ${ }^{41}$.

La leche podía, en lugar de estropearse, perderse:

$\begin{aligned} & \text { Mentre ho estava dient l'infantonet crida: -Dida, } \\ & \text { ai dida, deu-me mamar que ganeta jo tenia. }\end{aligned}$
-Qué li'n daré al meu fillet que la llet m'en ha fugida.
- Aneu-se'n al galliner mateu la millor gallina.
Si d'una no n'hi prou mateu-ne quantes n'hi haurie ${ }^{42}$.

Si las cualidades morales pueden llegar al niño a través de la leche de la nodriza, no cabe duda de que los alimentos ingeridos por ella tam-

40 Semanario Pintoresco Español, 1837, p. 83, cfr. Colette RABATÉ, "Mères et nourrices dans la littérature espagnole entre 1834 et 1860", Iberica, 1 (1992), pp. 143157: 152. Mme. CELNART, en su Manuel des nourrices (Paris: 1834) comenta los mismos hechos, casi con los mismos términos: "Les nourrissons des femmes colériques sont sujets aux diarrhées bilieuses, aux convulsions, parce qu'à la suite des acces de la colère, le sein ne fournit plus qu'un sorte de liquide face et jaunâtre, au lieu d'un lait blanc, doux et soucré», $c f r$. MARTiN-Fugier, p. 21. Ver además Guiral y Thuillier, p. 10. Contamos con el testimonio de un médico castellano del siglo XVII, quien establece todas las disposiciones necesarias para la perfecta salud de la nodriza y del niño: «[...] lo que comiere sea cosa, de que se engendre buena sangre; porque della ha de engendrarse la buena leche. Mas que coma moderadamente y beba poco. Allende desto hazer, que se evacue conforme al humor, que en ella pecare, y del qual recibe el daño la leche; porque las vexiguillas ulceras, y pustulas de la lengua, y boca de los niños, nacen de la acrimonia y mordacidad de la leche. Tengase cuidado de que la nodriça no se acalore, ni haga exercicio demasiado, si lo hiziere moderado, y antes de comer, y que se guarde de llegar a varón, porque el coitu es dañosissimon, Geronimo SORIANO, Metbodo y orden de curar las enfermedades de los niños (Zaragoza: Domingo Gascón, 1690), p. 38.

41 Ambas recogidas y publicadas por Arcadio DE LARREA, Romances de Tetuán (Madrid: CSIC, 1952), pp. 276-277. Ver Análisis, n. ${ }^{\circ}$ III.1 y III.2.

42 Fragmento recogido por Manuel MiLÀ I FONTANALS, publicado en Romancerillo catalän: Canciones tradicionales (Barcelona: Álvaro Verdaguer, 1882), pp. 39-40, variante K. Ver Análisis, n. ${ }^{\circ}$ II.12. 
bién se transmitirán. Este párrafo de La vida de don Gregorio Guadaña novela en buena medida algunas de las opiniones que hemos visto hasta el momento:

Ordenaron de darme ama. Hubo en esto diversos pareceres sobre la leche; llovía Galicia gallegas, y todas sobre un espejo daban rayos de vino disfrazado en cuajo; últimamente, le entregaron mi inocencia a una que pudiera apostar a beber secreto con hipócrita. Empecé a aplicar mis labios a sus dos pechos, tan grandes que parecían alcabalas de Baco. La cara de mi ama no diferenciaba de la de una loba, como lo era. Metiéronme en la cuna (primera sepultura del hombre) y con toda la música de Galicia no me harían dormir, si yo daba en llorar.

Ordenaron que durmiese con aquel pellejo que me alimentaba, y una noche que mi gallega tenía cuatro dedos de vino sobre los sesos, me quiso arropar con todo su cuerpo, pero yo que había bebido gran cantidad de mosto, empecé a levantar el chillido de tal suerte que levanté la casa, cuanto y más los que dormían en ella. Acudió mi madre y sus criadas, y llegándose a la cama, me hallaron debajo de aquella cuba casi para espirar; quitáronme la pesadilla que tenía encima, riñeron al ama, y pusiéronme en la cuna para que buscase la rebusca que le había quedado a mi gallega. No la despidieron, porque dijeron los médicos que no mudasen de amas si no querían que yo mudase de vida ${ }^{43}$.

A pesar del escaso entusiasmo de don Gregorio, la calidad de la leche que debía tomar el niño es estudiada con detalle por los autores médicos desde la Edad Media, lo que incluye pruebas sobre su color o textura ${ }^{44}$. Las creencias populares en torno a los motivos por los que puede perderse la leche son variados: puede deberse a que otra mujer o un animal hembra se coma las sobras de la madre, o porque los pañales del niño hayan sido expuestos a la luz de la luna, o porque se beba al mismo tiempo que se da la leche. Una culebra puede entrar por la noche en la habitación interponiéndose entre el pecho y el niño, llevándose la leche y calmando al niño con su cola; se puede saber si es esa la causa de los males de la criatura dejando ceniza o arena en el suelo de la casa y localizando su rastro ${ }^{45}$.

43 Antonio Enríquez Gómez, Vida de don Gregorio Guadaña, ed. de Charles Amiel (París: Ediciones Hispanoamericanas, 1977), p. 89.

44 BAU, pp. 187-8.

45 George M. FOSTER: "Folklore y costumbres del embarazo, nacimiento e infancia", La antropología médica en España (Barcelona: Anagrama, 1980), pp. 257-258. En el caso de que el niño no mejore, se le decía el siguiente conjuro: "Una culebra llegó / y de mil pechos mamó / pero la Virgen María / mamando la sorprendió. / Por beber de esa leche / yo te condeno / que por el día y la noche / andes arrastra por el terreno. / Y para que así ande / toda la vida / recemos a Dios un Padrenuestro / y un Avemaría", de Oliva de Plasencia, en J. M. DomínguEz, "La lactancia en la Alta Extremadura", Revista de Folklore, 1 (1988), pp. 147-157: 152. También recoge testimo- 
Es interesante destacar que igual que la mala calidad de la leche de la nodriza podía afectar al niño, los beneficios físicos también eran patentes, y una buena alimentación podía librarle de enfermedades:

-Quítale de ahí, Juanillo, y búscale una buena ama, que la libre de la peste y la dé leche aliviada ${ }^{46}$.

Mimar a la nodriza, por tanto, se convierte en consigna prioritaria en la casa con el fin de prevenir los males de origen físico, moral o sobrenatural que podían sobrevenirle al niño ${ }^{47}$. Las atenciones que recibe se

nios similares José Manuel FraiLE GIL, "Lagartijas, lagartos y culebras por la tierra madrileña: rimas y creencias", Revista de Folklore, n. ${ }^{\circ} 185$, pp. 162-170, en concreto en p. 166. La relación entre los niños, las serpientes y la leche no es privativa solamente de esas creencias sobre la lactancia, sino que figura en un buen número de cuentos, ver el artículo citado de Fraile Gil y el de Marlène ALBERT-LLORCA, "Le serpent, la mère et l'enfant", Le corps humain: nature, culture, surnaturel (Actes du $110^{\circ}$ congrès national des sociétés savantes, Montpellier, 1985) (Paris: CTHS, 1985), pp. 99-110. Por otra parte, en Compendio de la salud bumana, Johannes de Ketham ofrece la solución en caso de la pérdida accidental de la leche: "Si la mujer que cría le falleciere la leche deue beber agua miel o seruisia nueva (que es linaje de vino) en la qual se haya cozido fenojo. E empués coma del dicho fenojo e guárdese la hora de no beuer vino con ellas e venirle ha harta leche. O teme poleo mezclado con vino e con hueuo e beua dello cada mañana. O tome estiercol de mures o ratones, II onzas, e simiente de lechugas, I onza, e cristal fino, media onza, e sea todo fecho póluera. E tome della quantidad de vn hueuo cada mañana fasta nueue días e terna leche en habundancia. E también deue vsar de comer asselgas e bletas guisadas con queso viejo e darle mucha leche. O si quiere entrar en baño puédese fregar las espaldas con miel en que haya mezclado semiente de oruga puluorizada. E salida del baño apriétese los pechos e los tenga bien calientes e haura mucha leche", seguimos la edición abreviada de María Teresa Herrera Hernández (Madrid: Fundación Juan March, 1978), Serie universitaria, n. ${ }^{\circ} 53$, pp. 42-43. Ver también Juan Bethencourt Alfonso, Costumbres populares canarias de nacimiento, matrimonio y muerte (Santa Cruz de Tenerife: Museo Etnográfico-Cabildo Insular de Tenerife, 1985).

46 Otra versión inédita asturiana del romance La infanta seducida, recogida por Aurelio de Llano en Zureda en 1924 y conservada en el Archivo Menéndez Pidal.

47 Como consecuencia directa de la cualidad o cantidad de la leche, el niño podía sufrir diversos trastornos. Elementos médicos y creencias populares se mezclan en la explicación de las causas. Ver Francisco NúNez DE ORIA, Libro del parto bumano en el qual se contienen remedios muy vtiles y vsuales ... y a las enfermedades de los niños (Alcalá de Henares: J. Gracián, 1580) (BNM R/257), f. ${ }^{\circ}$ 82r. Una de las causas que puede afectar al bienestar del niño es que sufra mal de ojo o la visita de alguna bruja. La documentación sobre el tema es tan extensa que ocuparía por sí misma, más que un artículo, todo un libro. Ver el trabajo de NúNez DE ORIA, cap. XXI completo, y los trabajos de Sebastián Cirac Estopañán, Los procesos de bechicería en la Inquisición de Castilla la Nueva (Tribunales de Toledo y Cuenca) (Madrid: CSIC, 1942); 
materializan en extras a su salario al cumplir el niño un año o al salirle el primer diente ${ }^{48}$. Tener una nodriza en casa es, más que una necesidad, un signo de poder económico en la medida en que a los gastos de manutención hay que sumar su sueldo ${ }^{49}$, las primas ${ }^{50}$ y los antojos, que, sabiéndose centro de atenciones, no debían de ser escasos ${ }^{51}$.

Julio Caro Baroja, Magia y brujería (San Sebastián: Txertoa, 1987), Las brujas y su mundo (Madrid: Alianza editorial, 1966), y Brujería vasca (San Sebastián: Txertoa, 1992, 5." ed.), quien menciona casos de ahogamientos provocados por brujas. Resultan éstos interesantes porque permiten ofrecer un punto de vista diferente de las causas por las que se creía que el niño podría haber muerto: "De allí se fueron a la aldea de Irautits, a casa de uno llamado Sorsail, donde Menioin y d'Armore cogieron a un niño en su cuna; y no pudiéndoselo llevar y ante el temor de ser descubiertos, lo estrangularon, habiendo abierto la puerta con el dedo, porque no se abría sino con una clavija. Después pusieron al niño en el lecho, entre su padre y su madre, para que el padre creyera que la mujer lo había ahogado por asfixia", p. 164. Es interesante por otra parte que en los casos en los que aparece una nodriza cuidadora del niño al morir la criatura es acusada por la comunidad la bruja, no el ama por descuido, $c f r$. p. 207, donde el niño es hijo de la bruja. La nodriza también salva al niño al reconocer a la bruja que se presenta por la noche para matarlo, p. 256 . Una de las formas de matar al niño era provocando el sueño del adulto que lo vigila, p. 98. Algunos de los casos de brujería se relacionan en su proceso con el tema La nodriza del infante: "Uma mulher estava a criar uma criança de peito, mas tinha bigado com uma vizinha que diziam que era feiticeira. Ela, para se vingar, fez uma desfeita à mãe da criança. Entrou de noite no quarto dela, pegou no filho sem ela dar por isso e foi botá-lo na chaminé entre as cinzas de lareira. Para a banda da manhã, ele deu em chorar muito. A mãe acordou e não viu no berço. Levantou-se, correu os cantos de casa e encontrou o filho entremeio das cinzas. Então, essa vizinha botou-o ali, que era para quando ela acendesse o lume queimar o filho", J. H. Borges Martins, Crenças populares da ilha Terceira, II (Lisboa: Salamandra, 1994), n. ${ }^{\circ} 19$, pp. 105-106. Un caso similar es estudiado por Annie MoliniÉ-BERTRAND, "Des sorcières dans la tormente", Les langues neo-latines, n. 289 (1994) II: Hommage à Charles Vicent Aubrun, pp. 7-16.

48 Ver los numerosos ejemplos que ofrece CORTÉs ECHANOve, op. cit.

49 Salarios de la inclusa de Madrid. 1587-1606: 4.896 maravedís/año en 1691-1700: 7.344 maravedís/año, $c f r$. Claude LARQuIE, "Les milieux nourriciers des enfants madrilenes au XVII ${ }^{\mathrm{e}}$ siècle", Melanges de la Casa de Velázquez, 19 (1983), pp. 221-242. Las que mejores salarios disfrutan son las nodrizas de la Casa Real, ver CORTÉs ECHANOvE. Salario de 20 francos/mes en el siglo XIX en Francia, $c f r$. LE FORT, p. 377. Ver también Fernando CORTÉs CORTÉs, "Atenciones a los expósitos en la Extremadura del siglo XVIII", Studia bistórica, Historia Moderna, XII (1994), pp. 137-156, y en concreto pp. 139, 143 y 144.

50 Al primer diente del niño se le regalaba un vestido, una medalla, $c f r$. Jacques et Claude SeIGNOlle, Le folklore du Hurepoix (Paris: Maisonneuve, 1937), p. 36, Claude SEIGNOlLe, Le folklore du Languedoc (Paris: Maisonneuve, 1960), p. 31; un lazo de perlas y oro para la nodriza de Carlos II, CORTÉs ECHANOve, p. 89.

51 Podemos saber el tratamiento alimenticio que recibía la nodriza por boca de una mujer de Pinofranqueado (Cáceres) que lo fue en los años veinte: "Jui a Cazri pa 
De nuevo encontramos en el romancero referencias al tema, incluso al salario que debía pagarse:

-Que tomeis a Blancaniña, la llevex a una judía, que la mire bien mirada y dexle un ducado al día.

(El conde Alarcos + La fuente fecundante $)^{52}$

La buena nodriza tenía asegurado el empleo en la propia casa o con sus referencias en otra casa de la ciudad ${ }^{53}$, pero si su trabajo se había realizado en la corte, los beneficios de su vinculación con ella podían convertirse en oficios para el marido o los hermanos de leche del niño a su cuidado ${ }^{54}$. De ahí el verdadero significado económico de la frase que acompaña al destierro de la nodriza:

crial a un niñu y jui con el míu, que ya ehtaba creciinu... Cuandu llegue antovia no ehtaba nacíu, y al desotru día nació, qu'era el 24 de mayu... Al míu lo dehtetarun con venga a daili sopa de lechi... Era to pa que la mi teta juera toa pal otru niñu... Dendi luego que a mí me cebaban com'una lichona, pa sacalmi bien la grasa: galletah, fidéuh, churruh, pollu, cuchulati..., que p'al pueblo éhti solitu se lo daban a loh mediu defuntuh. Asín que me truji alguna perrina de cuasi dos añuh, poh golví pa la cruz del Casalm, en Domínguez, p. 155. La opinión de los padres no puede exponerse de manera más clara: "¿Y qué dirías si en tu casa se hubiera abrigado una serpiente, una ama de cría, cuyos antojos y caprichos es necesario cumplir a toda costa, a fin de que no se agrie la leche del niño que amamanta?" J. M. ANDUEZA, Trabajos y miserias de la vida (Madrid: Boix, 1842), p. 163, cfr. RABATÉ, p. 154. Resulta interesante contrarrestar la imagen de la denominada 'lactancia mercenaria' con la teoría presentada en el artículo de Miquel BORREL I SABATER, "Las amas de cría en el corregimiento de Girona en el siglo Xvill: una interpretación sobre las causas de la lactancia de los niños expósitos", Espacio, Tiempo y Forma: Historia moderna, 8 (1995), pp. 221-240. Considera Borrel que muchas de las amas de cría no mercenarias del hospital de Sta. Caterina no tenían intereses económicos al presentarse como nodrizas, sino que se consideraba la leche como un don de Dios, más que como un alimento, por lo que en ocasiones en el caso en el que por diferentes circunstancias el recién nacido no pudiera disfrutarlo, se daba a hermanos mayores o incluso adultos, $c f r$. p. 229. El sentido de la caridad haría el resto. Estas amas a diferencia de las mercenarias mantenían durante más tiempo la lactancia al bebé asignado, ver p. 230. Como decíamos, este trabajo realizado sobre la documentación del archivo del hospital permite ofrecer un nuevo punto de vista sobre las nodrizas.

52 Versión inédita de Salónica, procedente del manuscrito de Isaac Bohor Amaradjí, conservada en el Archivo Menéndez Pidal, Catálogo Armistead, L1.1.

53 De hecho se recomendaba entregar certificados que probaran la buena conducta de las nodrizas que realizaran bien su trabajo con el fin de localizar a las que se mostraban negligentes en él. Ver Miguel Ouva DE SABUCA, Nueva filosofía de la naturaleza del bombre (Madrid: P. Madrigal, 1587) (BNM R/31054), f. 41.

54 Carmen SARAuSA, Criados, nodrizas y amos (Madrid: Siglo XXI, 1994), p. 183, n. 77. Ver numerosos ejemplos en el indispensable trabajo de CORTÉs ECHANOVE y en 
- Coge la rueca y el huso, vete por el mundo alante pudiendo estar en mi casa la mantellina terciada,

como una mujer mundana,

bien querida y estimada. (II.30) ${ }^{55}$

Sin embargo, el peligro que corre el niño dado a un ama también se extiende, como comentábamos, a los males morales, pues la leche transmite mucho más que enfermedades ${ }^{56}$. Así se recoge, por ejemplo, en los autos de la Inquisición:

la obra de Isabel Beceiro Pita y Ricardo Córdoba de la Llave, Parentesco, poder y mentalidad. La nobleza castellana siglos XII-XV (Madrid: CSIC, 1990), p. 113 y n. 12. Conocido es el ejemplo mencionado por don Juan Manuel: "Alfonso García, un cavallero que me crió, que era mucho ançiano et se criara con mio padre et era su hermano de leche", Libro de las armas, p. 122. No podemos dejar de citar la burlona referencia a la nodriza de Esteban González: "nuestra madre le decía que yo era mayorazgo de su casa y cabeza de su linaje y descendiente del conde Fernán Gonzales, cuyo apellido me había dado por línea recta de varón; y por parte de hembra [...] una tía mía había dado leche al infante don Pelayo, antes que se retirara al valle de Covadonga..., Vida y bechos de Estebanillo González, ed. Antonio Carreira y Jesús Antonio CID (Madrid: Cátedra, 1990), t. I, p. 42.

55 En el romance de las Quejas de doña Urraca estos versos estaban vinculados más que con el destierro con el ejercicio de la prostitución: "Yrme yo por essas tierras / como vna muger errada // y este mi cuerpo daria / a quien se me antojara: // alos moros por dineros / y alos christianos de gracia; // delo que ganar pudiere / hare bien por la vuestra alman, Cancionero de Amberes, s.a., ed. facsímil de Ramón MENÉNDEZ PIDAl (Madrid: CSIC, 1948), f. ${ }^{\circ}$ 158r-v. Sin embargo, en el romance de La nodriza del infante la modificación que introduce el tercer verso, la comparación entre la situación que podría disfrutar en la corte y la que va a tener, es el verdadero estructurador del castigo por el destierro.

56 De hecho, Hipócrates, Galeno y Huarte de San Juan habían relacionado los humores con la enfermedad en general. Ver F. Azouvi, "La mujer como modelo de patología en el siglo XVIII", Diógenes (1981), n. ${ }^{\circ} 115$, pp. 23-4, y José AmEzCuA, "Mujer y enfermedad en El médico de su honra calderoniano", Nueva Revista de Filología Hispánica, XIII (1994) 1, pp. 87-98. Por otra parte, en el siguiente símil de Cicerón podemos ver también la imagen de la nodriza como transmisora mucho más que de alimento: “[...] en realidad de cuanto hacemos y afrontamos la vida, continuamente andamos en medio de una depravación general y una misma prevaricación de juicio; de manera que parece que libamos con la leche de la nodriza del error", Tusculanas (Madrid: Coloquio, 1986), p. 144. Conocidos son los ejemplos de las nodrizas-animales que transmiten sus cualidades a los niños que alimentan, así Luis Vélez DE GuEVARA, en El cerco de Roma por el rey Desiderio, pone en boca del monarca la siguiente bravata: "Una tigre fue mi madre, / crueldad mamé de su pecho / aunque en las iras me rindo, / en las crueldades me templon, ed. de Henryk Ziomek y Ann N. Hugues (Kassel: Reichenberger, 1992), vv. 65-68, p. 48. El refranero, como es lógico, se hace eco de estas creencias: "La primera mamada, de mujer honrada", CASTILLO DE LUCAS, Medicina en refranes, p. 26; "lo que en la leche se mama, en la mortaja se derrama", "lo que en 
Después en enero de este año de 74 , habiendo hecho más largas confesiones como está dicho, pidió audiencia y dijo que la había pedido para manifestar la verdad, que estaba todavía en la ley de Moisés, que como la mamó en la leche ${ }^{57}$, cuando le daban inspiraciones de volverse a la fe de Nuestro Señor Jesucristo, pensaba que se le había de perder su ánima y estaba en gran confusión ${ }^{58}$.

De hecho, en la primera versión que hemos mencionado de El bijo póstumo acaso se reflejan los prejuicios sobre la mujer morena como posible descendiente de árabes ${ }^{59}$. En el romancero también se reflejan estos prejuicios:

De un mes y catorce días dijo el niño con su boca:

-Alto, arriba, madre amada, alto arriba, pecadora

que la leche de tus pechos mantención de a mi persona,

la leche se mama, hasta la sepultura acompaña", que fue recogido por el Marqués de Santillana con ligeras variantes: "lo que en la leche se mama en la mortaja sale", en Refranero, ed. de María Josefa Canellada (Madrid: Novelas y cuentos, 1980), p. 119; CASTILLO DE LuCAS en su Refranero médico, p. 181, también indica otros como: "cuál el ama, tal la cría", "Lo que se aprende con la leche en los labios, no se olvida con los años", "Lo que se aprende —o se mama- en la cuna, hasta la muerte duran, p. 183.

57 Sebastián de HoROzco recoge esta frase proverbial y su glosa documenta muchas de las afirmaciones que hemos visto hasta la fecha. Así comenta que "no ay duda sino que en la leche se toma la bondad o maldad [...] que ha de tener la criatura adelante y no solamente en la sanidad o enfermedad más aún en la buena o malas costumbres segund la buena o mala leche que maman. Ilustra la afirmación con el siguiente ejemplo: "Y no piense alguno que es hablilla lo que se dize del hombre que se revolcaba en el çieno por aver mamado leche de puerca porque muchos sabios varones lo escriben [...]. Seguimos la ed. de Jack WEINER del Libro de los proverbios glosados (Kassel: Reichenberger, 1994), vol. I, p. 92. El refrán "Lo que en la leche se mama, en la mortaja se derrama", está documentado en Gonzalo de CoRrEAs, Vocabulario (Madrid: Tipogr. RABM, 1924), p. 271, y está recogido en el Diccionario de Autoridades, LECHE. Las connotaciones de la frase "mamolo en la leche" varía sin embargo de una fuente a otra: mientras que Correas comenta "tómase en mala parte" (p. 290), el Diccionario de Autoridades se limita a señalar que es "Lo mismo que aprender alguna cosa en la niñez. Sebastián de Horozco, por su parte, tan sólo remite en su comentario a los elementos negativos: "Eso viene de criança porque mamó mala leche o porque es malo desde que naçión.

58 La inculpada es Isabel de San Juan, de Baeza. Testificó contra ella su cuñado, el licenciado Juan Infante, médico, que acusó a toda su familia política. Cfr. Rafael Gracia Borx, Autos de fe y causas de la Inquisición de Córdoba (Córdoba: Diputación Provincial, 1983), p. 135.

59 El tema ha sido estudiado por Julio CARO BAROJA en Las formas complejas de la vida religiosa (Madrid: Akal, 1978), pp. $489-493$ y Los judios en la España moderna $y$ contemporánea (Madrid: Arion, 1962), t. II, p. 306; ver también José María PERCEVAL, "Qué hacer con los niños moriscos?", Historia 16 (mayo 1989), n. . 157, pp. 133-136. 
primero tú la enturbiaste para de ahí venir a mi boca.

¿Permites que pierda el cielo y los reinos de la gloria? (San Alejo) ${ }^{60}$

Lógicamente, la situación contraria, la salvación del alma, es posible:

Su padre es un rey moro, su madre una renegada,

la varen donar a criar a una dida cristiana.

La dida, la bona dida la doctrina li ensenyava.

El dia que-ho va sabé su padre l'atormentava. (Santa Catalina) ${ }^{61}$

En ciertos casos, el niño puede rechazar a la nodriza también por motivos religiosos:

Mandaran por las madrisas que dieran leche a Mosé.

Mosé como era nabí no quiZo leche de misrí;

mandaron por Yojebet que diera leche a Mosé

y Mosé no lo quiZo hasta que se lo pagó. (Nacimiento de Moisés) ${ }^{62}$

Mención aparte merece el hecho de que sea en ocasiones necesario encontrar a dos o más mujeres para que alimenten al niño. Como vemos, no sólo era importante la supuesta calidad de la leche, sino también su cantidad:

Almançor se holgo con él a dos amas lo auia dado

para que muy bien lo crien y con muy grande recado ${ }^{63}$.

-iOh, bienhaya don Manuel, y la leche que has mamado!

Mamaste leche de tres, ojalá fuera de cuatro. (Don Manuel y el Moro Muza) ${ }^{64}$

60) La flor de la Marañuela (Madrid: Centro Seminario Menéndez Pidal-Gredos, 1986), t. I, p. 111, n. $^{\circ} 66$.

61 MILÀ, n. ${ }^{\circ} 24$, p. 26.

62 En J. MARTínez Ruiz, "Poesía sefardí de carácter tradicional (Alcazarquivir)", Archivium XIII (1963), pp. 79-214: 135, vv. 14-17. Aclara en nota que 'madrisas' significa nodriza, tal vez por cruce de madre con nodriza, la forma matrix, popular, se documenta en 1490 en el Universal Vocabulario de Alonso FerNÁNDEZ DE PALENCIA, 31d, $88 \mathrm{~d}$ y $164 \mathrm{~b}$. En el sentido señalado no figura en Corominas, III, p. 182n.

63 Se trata del romance con incipit "Una hermana de Almançor / Rey de Cordoua llamadon, publicado por Lorenzo de SEPÚlVEDA, Cancionero de Romances (Sevilla, 1584), ed. Antonio Rodríguez-Moñino (Madrid: Castalia, 1967), p. 187-188, estos versos en p. $187 a$.

64 José María Cossío y Tomás MAZA SOLANO, Romancero popular de la Montaña, t. I, n. ${ }^{\circ} 28$, pp. $62-63$. 
En La nodriza del infante encontramos algunas versiones en las que expresamente se justifica la necesidad de tener que encontrar a otra mujer que alimente al niño en vez de su madre:

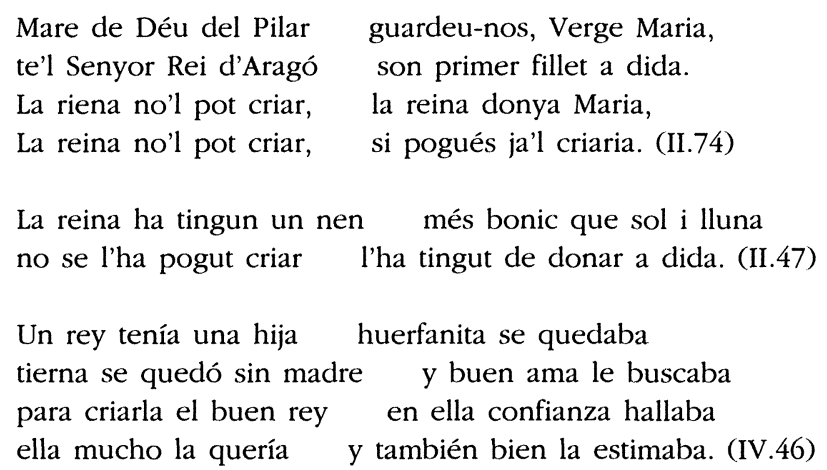

Se trata de exordios que introducen el romance del mismo modo que lo hacen los romances vulgares o de ciego. La presencia de estos incipit se produce en escasas versiones de la tradición y en época relativamente reciente en la historia del romance. Probablemente su inclusión se deba a que, desde el punto de vista del transmisor, se necesite justificar la decisión de dar el niño al cuidado del ama, lo que no debe entenderse como que la madre, la reina, abandona sus obligaciones, sino que por diversas causas no puede alimentar a su hijo. Es decir, el romance se hace eco del cambio de opinión que se ha producido en la sociedad con relación a las nodrizas.

El cariño que el niño siente por su ama puede suponer que prefiera las atenciones de ésta a las de su propia madre:

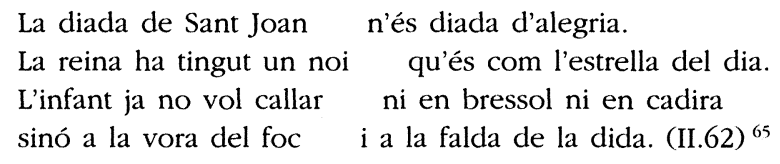

La situación que se plantea en el romancero remite a una realidad concreta tanto en la península como en el ámbito francés y sefardí. La figura de la nodriza, centro de atención al encargarse de los cuidados del niño, recibe un tratamiento bien diferenciado entre la literatura popular y la obra de escritores, médicos y teólogos de la época, aunque algunas de las opiniones generales son comunes en los dos ámbitos. El romance filtra preocupaciones y refleja conflictos de la vida real, junto con creencias 
que se van modificando a lo largo de su transmisión oral, como reflejo de la mentalidad de la comunidad que lo transmite.

La nodriza del infante es una balada tradicional que se documenta en lengua castellana, catalana, francesa y sefardí. Las numerosas referencias a las nodrizas en éste y en otros temas romancísticos se relacionan con las ideas expresadas por moralistas, teólogos y médicos, desde la Edad Media a nuestros días. Así se intentan establecer los puntos de acuerdo y de desacuerdo con la comunidad depositaria y transmisora del romancero oral tradicional.

La nodriza del Infante (The Prince's Nurse) is a traditional ballad documented in Catalan, French, Sephardic and Spanish. The numerous references to wet-nurses in this and other ballads are related to the ideas that moralists, theologians and physicians expressed about wet-nurses, from the Middle Ages to the present. By comparing those references with these ideas, the author aims to identify the points of agreement and disagreement between such scholarly tradition and that of the community that has orally preserved and transmitted ballads. 